\title{
Práticas sociais estratégicas e resultados acadêmicos: o doutorado em administração na USP e na UFRGS*
}

\author{
Diego Iturriet Dias Canhada** \\ Sergio Bulgacov***
}

\begin{abstract}
SumáRIo: 1. Introdução; 2. Estratégia como prática social; 3. Pós-graduação stricto sensu e o doutorado em administração no Brasil; 4. Metodologia da pesquisa; 5. Resultados da pesquisa; 6. Complementos dos resultados; 7. Considerações finais.

Summary: 1. Introduction; 2. Strategy as a social practice; 3 . Doctoral and other postgraduate courses in administration in Brazil; 4. Research methodology; 5. Research findings; 6 . Complements to findings; 7. Final remarks.
\end{abstract}

Palavras-chave: práticas sociais; estratégia organizacional; resultados acadêmicos; doutorados em administração.

KEY WORDs: social practices; organizational strategy; academic results; $\mathrm{PhD}$ in management.

Este trabalho teve como objetivo identificar as práticas sociais que sustentam resultados acadêmicos superiores em dois programas de doutorado em administração: USP e UFRGS. Utiliza como indicador de resultados acadêmicos a avaliação trienal da Capes (2004-2007). Emprega uma abordagem epistemológica interpretativa e social construtivista e tem como orientação teórica a corrente conhecida como estratégia como prática social. O referencial teórico é constituído de dois tópicos que discutem: a estratégia como prática social; pós-graduação stricto sensu e doutorado em administração no Brasil. A pesquisa empírica foi de natureza qualitativa e se

\footnotetext{
* Artigo recebido em ago. 2010 e aceito em nov. 2010.

** Mestre e bacharel em administração (estratégia e análise organizacional) pela Universidade Federal do Paraná (UFPR). Endereço: Centro de Pesquisa e Pós-Graduação em Administração (Ceppad) da UFPR. Av. Brasílio Itiberê, 3389, AP22B — Água Verde — CEP 80250-160, Curitiba, PR, Brasil. E-mail: diego_canhada@yahoo.com.br.

**** Pós-doutorado em estratégia pela University of Birmingham e doutor em administração pela Fundação Getulio Vargas - São Paulo (FGV-SP). Professor Associado ao Ceppad (UFPR). Endereço: Rua José Francisco Dalledone, 105, casa 6 - São Lourenço — CEP 82200-250, Curitiba, PR, Brasil. E-mail: s.bulgacov@gmail.com.
} 
constitui em uma análise comparativa de casos. Entre os principais resultados da pesquisa, evidencia-se que determinadas características e atividades da coordenação, dos doutorandos e dos professores são relevantes, como: comprometimento e dedicação, por parte dos doutorandos; valorização da pesquisa e estar em contato com o mundo real das organizações, por parte dos professores; coordenar o programa e proporcionar incentivos com base nas métricas da Capes, por parte da coordenação dos cursos. Com relação às práticas coletivas, destaca-se a atuação de todos os atores em grupos de pesquisa e com produção científica em conjunto.

\section{Strategic social practices and academic results: a doctorate in management at USP and UFRGS}

This study aims to identify the social practices that support higher academic achievement in two doctoral programs in management: USP, UFRGS. Using as an indicator of academic achievement the Capes (2004-2007) indicators and as epistemological approach interpretationism. The theoretical background is the social constructivist with the framework known as the current strategy as social practice consisting of two topics, post-graduate and doctorate management programs in Brazil. The empirical research was qualitative and constitutes a comparative analysis of two cases. The most important results of this research shows that certain characteristics and activities of the coordination, the professors and the doctoral students are important, such as: commitment and dedication of the students; enhancement of research and be in touch with the real world of organizations as an important role of the professors, provide incentives based on metrics from Capes, by the coordination of the courses. With respect to collective practices, highlight the importance of all actors in the research groups.

\section{Introdução}

O ensino de administração no Brasil tem sido foco de muitos estudos e discussões no meio acadêmico nacional, como tem mostrado o aumento no número de publicações nos eventos da Associação Nacional de Pesquisa e Pós-Graduação em Administração (Anpad) e nas principais revistas especializadas do país sobre o tema em questão. No entanto, a maioria dos trabalhos publicados no país tem foco na graduação, alguns deles na especialização e MBAs, mas há poucos trabalhos sobre o sistema de pós-graduação stricto sensu. Em relação aos estudos sobre cursos de doutoramento em administração, percebe-se um número muito menor de reflexões acerca desses cursos do que no nível de mestrado. Rara exceção é o trabalho de Pereira e outros (2002), publicado no Enanpad de 2002 e elaborado com base no curso de doutorado em administração da UFRGS, que explora de forma aprofundada 
as responsabilidades de alunos, professores e da instituição em um curso de doutorado em administração.

Este trabalho buscou cumprir essa lacuna, que é a falta de estudos sobre esse tema, e dar continuidade aos esforços de Pereira e colaboradores (2002), atendendo às recomendações para futuras pesquisas feitas por eles e entendendo que a formação doutoral em administração acaba por influenciar todos os outros níveis de ensino e pesquisa na área. A relevância desse papel é acentuada quando se verifica que o curso de administração é hoje o que concentra o maior número de estudantes do país (Sauerbronn e Oliveira, 2007).

Para realizar esse trabalho, optou-se pela análise dos programas de doutorado em administração das instituições de ensino superior públicas que conseguem atingir os melhores resultados acadêmicos, de acordo com a avaliação da Coordenação de Aperfeiçoamento de Pessoal de Ensino Superior (Capes). Isso se justifica pelo fato de que embora possa haver algumas críticas ao sistema de avaliação da Capes, o mesmo ainda é considerado o indicador mais confiável de qualidade dos cursos de pós-graduação stricto sensu no país. Esses cursos de doutorado atualmente encontram-se na Universidade de São Paulo (USP) e na Universidade Federal do Rio Grande do Sul (UFGRS), que possuem programas de doutorado em administração já consolidados e considerados de alta qualidade. O curso de doutorado em administração da Fundação Getulio Vargas de São Paulo (FGV-SP), que também é avaliado como um dos três melhores do país, não foi objeto de investigação especialmente por dois motivos: limitação de tempo para realizar a pesquisa empírica e por não ser uma instituição pública, o que dificultaria a análise comparativa.

A avaliação da Capes está fundamentada na proposta do programa, corpo docente, atividade de pesquisa, atividade de formação, corpo discente, teses, dissertações, produção intelectual e inserção social (Capes, 2008a). A análise desses cursos foi realizada com o referencial teórico da corrente de pensamento conhecida como "estratégia enquanto prática social" (Whittington, 1996; Whittington, Johnson e Melin, 2004; Jarzabrowski, 2005). Buscou-se compreender quais são as práticas sociais que sustentam resultados acadêmicos superiores, de acordo com a interpretação dos principais atores envolvidos nesse processo: coordenadores do programa, professores e alunos. Isso sem desconsiderar o contexto histórico, social e organizacional em que as práticas sociais se realizam.

Entende-se que estudar a estratégia de uma organização é estudar também os resultados de suas ações (Chakravarthy e White, 2002; Whittington, Johnson e Melin, 2004; Jarzabrowski, 2005), que são muitos e não apenas financeiros, como tradicionalmente o campo de estudos tem investido esforços. 
Uma organização atinge diversos resultados em sua existência (Scott, 2003; Hall 2004) e neste trabalho opta-se por partir de resultados dados a priori, sendo esses resultados acadêmicos oriundos da avaliação institucional da Capes em relação aos cursos de formação doutoral. Nesse sentido, o problema de pesquisa que norteou o trabalho foi: "Quais são as práticas sociais que sustentam resultados acadêmicos superiores em um programa de doutorado em administração no Brasil considerado de alta qualidade, de acordo com a interpretação dos principais atores envolvidos no processo?"

Para responder a esse problema de pesquisa, este trabalho está organizado em sete partes, incluindo essa introdução como a primeira delas. A segunda parte discute a estratégia como prática social. A terceira parte discute a pós-graduação stricto sensu e o doutorado em administração no Brasil. A quarta parte apresenta a metodologia de pesquisa utilizada. Na quinta parte apresentam-se os resultados da pesquisa. Na sexta parte, apresentam-se complementos dos resultados que emergiram do trabalho de campo e auxiliam na compreensão dos resultados obtidos. Na última parte do artigo, reservada às considerações finais, reflete-se sobre algumas concepções que auxiliam no entendimento dos aspectos sociais envolvidos em uma estratégia organizacional.

\section{Estratégia como prática social}

Percebe-se que, embora o campo dos estudos organizacionais seja interdisciplinar há longa data, a economia sempre foi a disciplina central que guiou a área de estratégia. Com o foco predominantemente econômico, alguns aspectos como a prática da estratégia ficaram sem espaço ou relegados a um papel secundário nas pesquisas acadêmicas. Aos poucos, os estudos em estratégia foram sendo enriquecidos com aportes teóricos de outras disciplinas da área das ciências sociais e humanas (Mintzberg, Ahlstrand e Lampel, 2000), mas é com a corrente denominada estratégia como prática que a teoria social contemporânea, em especial a sociologia, foi incorporada definitivamente aos estudos da área (Wilson e Jarzabrowski, 2004; Whittington, 2004).

Entendida como uma prática social, a estratégia evidencia as microatividades (processos) realizadas pelos indivíduos, que em constante interação e envolvidos em complexas relações de poder e significados compartilhados na organização, permitem que ela tenha resultados (conteúdo) desejados ou não. A partir desse entendimento do foco de pesquisa e muito influenciados pela teoria institucional de base sociológica, os teóricos dessa corrente eviden- 
ciaram o fato de que a estratégia é contextualizada e precisa ser entendida dentro de um ambiente sociocultural específico. As ferramentas e conceitos utilizados pelos atores organizacionais são tomados de seu meio através das instituições e de processos de socialização (Berger e Luckmann, 2003; Meyer e Rowan, 1977; Dimaggio e Powell, 1983; Scott, 2001, 2003), como: escolas de administração, empresas de consultoria, editoras de livros de estratégia. Mais do que apenas usá-los de forma neutra, os atores organizacionais interpretam e atribuem determinados significados a esses modelos, técnicas e teorias para colocá-los em prática de um modo específico. Com isso, a perspectiva da estratégia como prática relaciona atividades organizacionais realizadas pelos indivíduos com seu contexto ambiental em uma análise que pode ser chamada de vertical, bem como relaciona essas atividades (processos) com seus resultados (conteúdo), em uma análise que pode ser chamada de horizontal (Whittington, Johnson e Melin, 2004).

Entender a estratégia como uma prática é vê-la como uma atividade situada, realizada socialmente, construída por meio de ações e interações de múltiplos atores que realizam a prática estratégica, sejam eles estrategistas ou executores da estratégia (Jarzabrowski, 2005). Para Johnson e colaboradores (2007:7, tradução livre) a estratégia como prática "preocupa-se com o que as pessoas fazem em relação à estratégia e como isto é influenciado e influencia seu contexto organizacional e institucional". A estratégia como prática é entendida como um conjunto de atividades desempenhado nas interações e trocas sociais ocorridas nas organizações. A partir dessas atividades surgem práticas, formais ou informais, que constituem a estratégia. A prática da estratégia se dá tanto no processo de formação da estratégia (consolidado em episódios, por exemplo, as reuniões formais de formulação da estratégia) como na sua implementação (que começa com a interpretação dos discursos estratégicos pelos atores sociais responsáveis por esta prática). Essas práticas e atividades estratégicas acarretam vários resultados organizacionais que podem ser mensurados ou não. Caso exista mensuração, ela pode ser feita a partir de diferentes indicadores, sejam eles referentes a resultados econômicos, financeiros ou sociais.

Embora ainda haja muitas indefinições conceituais na perspectiva prática, em que se pode exemplificar a falta de clareza do que é uma prática em relação a processos e atividades individuais, conforme apontado por Chia e Mackay (2007), podem-se achar alguns pontos de confluência. Em um estudo orientado pela perspectiva da "estratégia como prática social", há interesse simultâneo pelas atividades (prática/práxis), práticas e praticantes que compõem a estratégia organizacional, bem como suas mútuas conexões (Jarzabro- 
wski, 2005; Whittington, 2006). Jarzabkowski (2005) propõe que o processo de formação da estratégia ocorre na confluência dessas três questões, conforme evidencia a figura 1 que se segue. Esses são os três elementos relacionados ao estudo da estratégia como prática.

\section{Figura 1}

Strategizing: as dimensões de análise da estratégia como prática

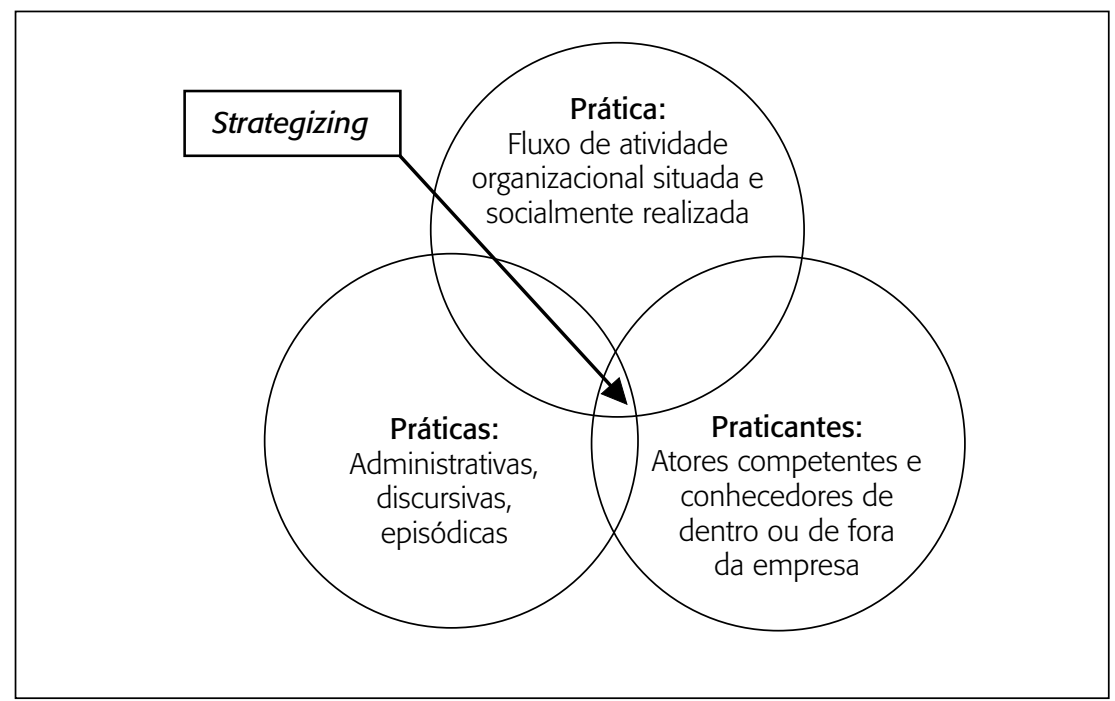

Fonte: Jarzabkowski, 2005 (tradução livre).

Jarzabkowski (2005) coloca que:

a 'prática' sob investigação é a estratégia como fluxo da atividade organizacional que incorpora conteúdo e processo, intenção e emergência, pensamento e ação e assim por diante, como recíprocos, inter-relacionados e frequentemente partes indistinguíveis de um todo quando observados de perto (Jarzabrowski, 2005:8. Tradução livre).

Por fim, concorda-se com Whittington (2007) e segue-se sua orientação de que, nas pesquisas em que é utilizada a abordagem da "estratégia como prática", mais importante do que qualquer posição teórica específica é a dinâmica do fenômeno a ser estudado. Nesse sentido, não se pretende utilizar dessa perspectiva para fazer a realidade em estudo adaptar-se ao referencial teórico, mas que esse sirva apenas como orientação para uma pesquisa em que 
as práticas, atividades e praticantes possam ter voz nesse trabalho que, com todas as limitações que possui, almeja ser um exercício de diálogo constante entre a teoria e a prática a ser estudada.

\section{Pós-graduação stricto sensu e o doutorado em administração no Brasil}

Os programas de pós-graduação no país surgiram após a regulamentação dos mestrados e doutorados em 1965 (Festinalli, 2005) e a história da pósgraduação stricto sensu confunde-se com a própria história da Capes (Ikeda, Campomar e Veludo-de-Oliveira, 2005), entidade governamental criada em 1951 com a finalidade de "assegurar a existência de pessoal especializado em quantidade e qualidade suficientes para atender às necessidades dos empreendimentos públicos e privados que visam ao desenvolvimento do país" (Capes, 2001). Vários autores (Schwartzman, 1979; Ramos, 2004; Ikeda, Campomar e Veludo-de-Oliveira, 2005; Festinalli, 2005) destacam a importância da Capes e/ou de sua avaliação institucional como responsável pela rápida expansão da pós-graduação stricto sensu no país e por sua consolidação como o nível de ensino mais bem sucedido do Brasil (Capes, 2001).

Schwartzman (1979) aponta que foram a expansão das matrículas de graduação, a criação de institutos centrais de pesquisas em universidades e os requisitos legais de diplomas de pós-graduação na promoção das carreiras universitárias que levaram as autoridades brasileiras a construir um sistema nacional de pós-graduação. No Brasil, esse sistema foi construído segundo o modelo norte-americano (Schwartzman, 1979; Festinalli, 2005) e sua institucionalização se iniciou com o Parecer 977/65 do Conselho Federal de Educação (CFE) — órgão extinto atualmente - e através do I, II e III Plano Nacional de Pós-Graduação que foram elaborados posteriormente (Festinalli, 2005). Até então, os títulos de mestrado e doutorado não eram dados regularmente pelas universidades brasileiras. Com a intenção de elevar a qualidade dos cursos de graduação no país, foi estabelecida a obrigatoriedade dos títulos de pós-graduação para os professores universitários (Schwartzman, 1979). Em relação a esses documentos, Festinalli (2005) afirma que:

O Parecer no 977/65, de 3 de dezembro de 1965, expedido pelo Conselho Federal de Educação (CFE), foi elaborado com o objetivo de conceituar os cursos de pós-graduação no Brasil, dando-lhes uma definição exata da sua natureza e fins específicos, para evitar as interpretações imprecisas que até então vinham ocor- 
rendo. Além de promover o esclarecimento do conceito e as características da pós-graduação, o parecer teve a incumbência de efetuar a sua regulamentação. Quanto aos Planos, em sua essência, procuraram apresentar um diagnóstico da situação do sistema da época a que correspondem e determinaram uma série de medidas que buscavam a consolidação do modelo adotado. A diferença entre eles é que o II e o III Planos são mais detalhados, as afirmações são baseadas em estudos sistematizados, predominantemente quantitativos, com o objetivo específico de fornecer dados para o estabelecimento de diretrizes, objetivos e metas para o período proposto (Festinalli, 2005:136).

Desde 1965 até hoje, a pós-graduação stricto sensu no Brasil teve um enorme crescimento e os cursos de mestrado e doutorado em administração também acompanharam esse movimento. O primeiro curso de pós-graduação em administração foi ofertado pela Fundação Getulio Vargas, no Rio de Janeiro, em 1967, na área de administração pública (Festinalli, 2005). Nos anos 1970, a pós-graduação stricto sensu sofreu um grande crescimento em todas as áreas, surgindo a maioria dos programas de administração hoje existentes e nos anos 1990 esse crescimento se acentuou (Pereira et al., 2002), crescimento que vem até nossos dias. Atualmente, com base nos dados de 2006 disponibilizados pela Capes, há 77 programas de pós-graduação stricto sensu em administração espalhados pelo país, sendo 39 apenas de mestrado, 17 de mestrado e doutorado e 21 deles de mestrado profissional (Capes, 2008b). Bom lembrar que especializações e MBAs, que são cursos de pós-graduação lato sensu, ficam fora dessas estatísticas, já que são cursos não avaliados pela Capes e com objetivos e finalidades muito diferentes dos cursos de pós-graduação stricto sensu.

A pós-graduação engloba cursos e programa de nível superior que vão desde cursos de aperfeiçoamento até o doutorado, incluindo especializações e mestrado. Nesse sentido, a pós-graduação tem por objetivos: formar professores para o magistério superior, com o propósito de atender a expansão quantitativa desses cursos, bem como assegurar sua qualidade, formar pesquisadores para trabalhos científicos e preparar profissionais de alto nível para instituições públicas e privadas (Oliveira, 1996). Sobre as diferenças entre as modalidades lato sensu e stricto sensu, Ikeda, Campomar e Veludo-de-Oliveira (2005) afirmam que esses estão voltados para uma perspectiva acadêmica, sendo composta pelos cursos de mestrado e doutorado. Aqueles referem-se aos cursos voltados às demandas do mercado, como especialização e MBAs. No entanto, o mestrado profissional, que se enquadra na modalidade stricto sensu, também é direcionado para o mercado, o que aumenta a confusão so- 
bre definições dessas modalidades (Ikeda, Campomar e Veludo-de-Oliveira, 2005).

Pereira e colaboradores (2002) evidencia que no Parecer no 977/65, o Conselho Federal de Educação (agora extinto) definiu que o doutorado "tem por fim proporcionar formação científica ou cultura ampla e aprofundada, desenvolvendo capacidade de pesquisa e poder criador nos diferentes ramos do saber" (Pereira et al., 2002:1). Este parecer, que permitiu aos cursos uma grande flexibilidade, estabeleceu os seguintes requisitos mínimos para conseguir a titulação de doutor: cursos de duração mínima de dois anos; são constituídos de estudos de matérias da área de concentração e de domínio conexo; uma tese; exames parciais e gerais; aprovação em provas que verifiquem capacidade de leitura em duas línguas estrangeiras (Pereira et al., 2002).

Eco (1977) afirma que quem obtém o título de doutor quase sempre empreende a carreira universitária. Embora nem todos possam estar planejando seguir carreira acadêmica, os cursos de doutorado têm por objetivo formar autoridades em determinado assunto, dominando-o até os limites do conhecimento, sendo capazes ainda de elevar esses limites (Pereira et al., 2002). Nesse sentido, a tese de doutorado seria um trabalho original de pesquisa, "com o qual o candidato deve demonstrar ser um estudioso capaz de fazer avançar a disciplina a que se dedica" (Eco, 1977:2). Assim, o autor afirma que deve ser um trabalho original, já que é necessário conhecer profundamente o que foi dito sobre determinado assunto, mas ir além disso e desvendar algo ainda não dito sobre o mesmo. Essa originalidade pode estar relacionada ao fato de uma nova teoria estar sendo desenvolvida, pode estar relacionada a uma nova metodologia de pesquisa que está sendo usada na pesquisa ou pode ser derivada do fato de que o domínio em que a teoria e a metodologia estão sendo aplicadas não tem sido previamente abordado desse modo (Remenyü et al., 2002).

Remenyii e colaboradores (2002) afirmam que para obter o título de doutor, o candidato necessita ocupar-se com um substancial programa de pesquisa e produzir uma tese que faça valiosa contribuição ao corpo de conhecimento da área. Para esse grau ser concedido, é essencial que a contribuição feita pelo pesquisador seja considerada pelos seus examinadores como tendo adicionado algo de valor para a disciplina que está sendo investigada, mesmo que seja uma contribuição modesta. É esperado que o candidato a doutor esteja familiarizado com a literatura de sua área de estudo e tenha amplo conhecimento e entendimento da disciplina em geral. O candidato deve mostrar que tem entendido e avaliado criticamente as principais questões no seu campo de estudos, já que é nessa avaliação crítica que surgirá a extensão no corpo de conhecimento pelo desenvolvimento de um novo aspecto na disciplina estu- 
dada. Por fim, espera-se que esses candidatos estejam familiarizados com o conjunto de metodologias de pesquisa disponíveis e que mostrem habilidade na organização e apresentação dos seus resultados de pesquisa, com clareza de expressão e do uso da linguagem (Remenyi et al., 2002).

Para Pereira e outros (2002), o conceito de doutor supõe uma autoridade reconhecida por uma faculdade. Isso significa ser um pesquisador profissional em uma área de conhecimento, em que esse pesquisador, de acordo com Philips e Pugh, citados por Pereira e outros (2002), tem algo a dizer de interesse de seus colegas; tem profundo conhecimento da sua área de forma a avaliar o trabalho de terceiros; é perspicaz para saber onde pode dar uma contribuição válida em sua área de conhecimento; domina as técnicas de pesquisa em uso corrente, conhecendo suas limitações; é capaz de divulgar os resultados de suas pesquisas; faz tudo isso em cenário internacional. Para que tudo isso ocorra, é necessário que um curso de doutorado propicie um ambiente para o desenvolvimento dessas habilidades. Para Pereira e outros (2002), os principais responsáveis pelo processo de doutoramento são os alunos, os professores e a instituição.

\section{Metodologia da pesquisa}

Esse é um estudo focado nas práticas sociais, tendo por base epistemológica uma abordagem interpretativa e social construtivista das ciências humanas. Embora existam muitas indefinições conceituais e metodológicas na perspectiva prática em estratégia, pode-se achar alguns pontos de confluência. Em um estudo orientado pela perspectiva da "estratégia como prática social", há interesse simultâneo pelas atividades (prática/práxis), práticas e praticantes que compõem a estratégia organizacional, bem como suas mútuas conexões (Jarzabrowski, 2005; Whittington, 2006).

Nesse estudo, consideram-se as atividades, prática e práxis como sinônimos, sendo que usaremos o termo atividade para não confundir com práticas. Atividade está relacionada ao desempenho dos atores no fluxo de ações organizacionais e seu domínio é amplo, incluindo rotina e não rotina, o formal e informal, ações centrais e periféricas. Atividades referem-se ao que as pessoas fazem no seu cotidiano organizacional (Jarzabrowski, 2005; Whittington, 2006; Johnson et al., 2007) e nesse trabalho foram consideradas aquelas realizadas individualmente pelos atores estudados - coordenadores de curso, professores e alunos e ex-alunos - , que eles percebem como significativas na manutenção dos resultados acadêmicos superiores no curso de doutorado. 
Práticas, por sua vez, referem-se a um conjunto de atividades que pertence a determinado contexto institucional e incluem normas e expectativas de comportamento, episódios estratégicos e rotinas ostensivas (Johnson et al., 2007). Dizem respeito a rotinas compartilhadas de comportamento, incluindo tradições, normas e procedimentos para pensar e agir (Reckwits, 2002a, 2002b; Whittington, 2006). As práticas são realizadas coletivamente (Craig, 2006), referem-se a um tipo rotinizado de comportamento que consiste de vários elementos interconectados (Reckwits, 2002a, 2002b; Hellmann e Rasche, 2007) e possuem grande significado para os envolvidos (Lounsbury e Crumley, 2007). Nesse trabalho, foram consideradas as práticas realizadas por mais de um ator e de forma rotineira, que eram percebidas como relevantes para sustentar os resultados superiores em um curso de doutorado em administração.

Os praticantes, em uma definição mais simples, são aqueles atores, inseridos na organização ou não, que desempenham suas atividades e realizam suas práticas, colaborando assim na construção da estratégia, ou seja, são as pessoas que efetivamente fazem a estratégia enquanto prática social (Jarzabrowski, 2005; Whittington, 2006). Neste trabalho, são considerados praticantes todos aqueles atores que foram identificados, primeiramente, na teoria e, posteriormente, na relação com o campo empírico, como colaborando na prática social que sustenta os resultados acadêmicos superiores dos programas de doutorado estudados.

A pesquisa se configura como exploratório-descritiva, seguindo classificação de Triviños (1994) e Gil (1999). Percebe-se elevada congruência nas classificações elaboradas por esses dois autores. Essa pesquisa se coloca como exploratório-descritiva, pois possui características desses dois tipos de pesquisa. O estudo procurou aumentar a experiência sobre determinado fenômeno, esclarecer e desenvolver determinados conceitos para futuras pesquisas, possuindo um caráter exploratório. No entanto, ao mesmo tempo procura descrever com exatidão fenômenos de determinado contexto e estabelecer relações entre categorias de análise. Com isso, colocando-se como um "entre tipos", o estudo classifica-se como exploratório-descritivo.

A estratégia de pesquisa utilizada foi o estudo de caso, com base nas definições de Yin (2001), mas principalmente indo ao encontro das considerações de Godoy (2006). O estudo de caso é uma estratégia que pode ser escolhida quando se examinam acontecimentos contemporâneos e não se podem manipular comportamentos relevantes, trazendo também a vantagem de propiciar a possibilidade de triangulação de dados (Yin, 2001). Godoy (2006) afirma que, como o estudo de caso deve estar centrado em uma situação particular, torna-se um tipo de pesquisa especialmente adequado: 
[...] quando se quer focar problemas práticos, decorrentes das intrincadas situações individuais e sociais presentes nas atividades, nos procedimentos e nas interações cotidianas. Embora o estudo de caso se concentre na maneira como uma pessoa ou grupo de pessoas trata determinados problemas, é importante ter um olhar holístico sobre a situação, pois não é possível interpretar o comportamento sem a compreensão do quadro referencial dentro do qual os indivíduos desenvolvem seus sentimentos, pensamentos e ações (Godoy, 2006:121).

Na classificação que essa autora elabora sobre estudos de caso, a pesquisa que aqui se realizou é um estudo de caso interpretativo. Isso porque procurou, além de uma rica descrição do fenômeno em estudo, uma padronização nos dados e desenvolver categorias conceituais no sentido de ilustrar, confirmar ou mesmo refutar as suposições teóricas desenvolvidas. É um estudo comparativo de casos, pois foram dois casos diferentes a serem estudados e comparados.

Esta pesquisa baseou-se em dados secundários e primários. Primeiramente, foram obtidos dados secundários a partir das informações disponibilizadas no site dos programas de pós-graduação stricto sensu em administração de cada um dos casos estudados, bem como das informações disponíveis no site da Capes, relativas à avaliação trienal realizada de 2007, que contemplou os anos de 2004 a 2006. Foram obtidas informações que permitiram uma aproximação inicial com os dois casos estudados, especialmente relativos às características organizacionais desses dois programas de pós-graduação, com foco específico nos cursos de doutorado. A partir dessa aproximação inicial, complementada com algumas conversas informais com pessoas que já conheciam esses cursos, iniciou-se uma fase de coleta de dados primários com imersão no campo empírico. O autor desse trabalho primeiramente estabeleceu residência temporária ao lado da USP e a estada em São Paulo durou 23 dias.

Nesse tempo, foram realizadas oito entrevistas semiestruturadas pessoalmente. Um professor do programa, que trabalha também na coordenação do departamento de administração, por sua impossibilidade de tempo para uma entrevista pessoal, respondeu ao roteiro de entrevistas por e-mail, totalizando nove respondentes. O método de identificação dos respondentes foi guiado pela base teórica da "estratégia como prática social", que afirma que os "gerentes de topo" são as pessoas mais importantes a serem contatadas primeiramente, mesmo sabendo que a estratégia e os resultados são construções sociais de vários atores.

Nesse sentido, a primeira entrevista foi com o coordenador do curso de doutorado e a partir desse contato e de conversa informal ao final da en- 
trevista, foi solicitada a indicação de mais respondentes que fossem pessoas importantes a serem entrevistadas, tendo em vista os objetivos da pesquisa. Assim, foram identificados outros atores importantes para os resultados do curso e esse procedimento foi repetido em todas as entrevistas, até que os mesmos nomes foram se repetindo e percebeu-se que se chegou a um número representativo dos praticantes estratégicos do programa, em um conjunto que envolveu coordenadores, professores e doutorandos.

Durante a estada em São Paulo, buscou-se aliar, às entrevistas, conversas informais, análise documental e observação não participante do cotidiano do curso de modo a enriquecer as análises. Dos nove entrevistados, quatro eram professores diretamente envolvidos com a coordenação do curso, ocupando cargos no departamento de administração e na coordenação da pósgraduação; três eram doutorandos indicados por seu envolvimento profundo com o curso e pelo desempenho acima da média; u era um professor identificado como excelente; um era um doutor recém-formado que fez uma tese propondo um modelo de gestão de programas de pós-graduação e indicado como uma das pessoas que contribuiu muito com o curso durante o tempo na instituição. Importante salientar que durante a estada na USP, aconteceu o Seminários de Administração (Semead), o que possibilitou ao pesquisador interagir e observar o envolvimento da coordenação, dos professores e dos doutorandos no evento.

Os procedimentos de coleta de dados para a UFRGS foram os mesmos adotados na USP, com uma entrevista inicial com o vice-coordenador do curso de doutorado e futuras indicações de respondentes. A estada em Porto Alegre durou 28 dias e durante esse tempo foram realizadas dez entrevistas semiestruturadas e mais três pessoas responderam por e-mail, por falta de tempo para uma entrevista pessoal ou por dificuldades de deslocamento do pesquisador, já que algumas não estavam mais no PPGA. Isso gerou um total de 13 respondentes.

Desses 13 respondentes, um professor era o vice-coordenador do curso; uma professora era decana do departamento; seis eram professores indicados como excelentes professores e pesquisadores; um era uma professora adjunta recém-contratada que cursou mestrado e doutorado no PPGA e foi agraciada com o Prêmio Capes por sua tese; um era um recém-doutor formado pelo PPGA que também foi agraciado com o Prêmio Capes por sua tese; três eram doutorandos do curso considerados de excelente desempenho, sendo um deles o representante discente da pós-graduação. Do mesmo modo que na USP, durante todo o tempo foram aliadas, às entrevistas semiestruturadas, observações não participantes, análise documental e conversas informais. Nos dois 
casos estudados, as entrevistas duraram cerca de meia hora, mas algumas delas passaram de uma hora.

Com relação às entrevistas realizadas e gravadas, seguiram-se as orientações elaboradas por Godoi e Mattos (2006), para posteriormente o material ser integralmente transcrito pelo próprio pesquisador e submetido a uma das técnicas de análise de conteúdo propostas por Bardin (2006), conhecida por análise temática. As entrevistas, mais do que técnicas para obtenção de dados, foram eventos dialógicos (Godoi e Mattos, 2006) em que os respondentes puderam reconstruir suas experiências de modo a realizar uma ressignificação das suas atividades individuais, práticas coletivas, características e resultados da organização em que atuam. Todas as entrevistas foram realizadas com um roteiro preestabelecido, em que as perguntas feitas eram praticamente as questões que respondiam aos objetivos da pesquisa. Com o material das entrevistas integralmente transcrito por parte do pesquisador, iniciou-se a análise de conteúdo. Seguindo recomendações de Bardin (2006), o material foi analisado de forma a elaborar inferências a partir dos dados coletados. Com base no modelo teórico elaborado, as categorias de análise foram selecionadas como temas e foram construídas tabelas no Editor de Planilhas Open Office que eram alimentadas com as informações obtidas.

Quando todas as entrevistas foram analisadas, iniciou-se a busca pelos significados compartilhados para cada categoria de análise/tema, de forma a construir a análise não mais das entrevistas individuais, mas dos casos em estudo, respeitando assim os pressupostos epistemológicos que guiaram o trabalho. Após esse procedimento para cada um dos casos, iniciou-se a análise comparativa desses, que buscou explicitar as similaridades e diferenças em cada curso de doutorado. Por fim, foram reunidas as observações adicionais, que se mostraram muito úteis especialmente na explicação do porquê das diferenças encontradas em cada caso.

Após o tratamento dos dados, todos os respondentes foram contatados para validar os resultados obtidos na pesquisa. Foi enviado e-mail a cada um dos respondentes e até o fechamento desse trabalho alguns respondentes tinham dado sua resposta. Na USP, o coordenador, vice-coordenador e um professor do programa responderam o e-mail e todos afirmaram que a tabela representava bem a realidade do doutorado em que eles estavam inseridos. Na UFRGS, o vice-coordenador do programa afirmou que o material retratava a realidade deles com bastante precisão,. Um dos professores respondeu dizendo que, caso ele tivesse feito a pesquisa, iria sugerir pequenas alterações, mas nada significativo e que no geral estava muito bom. Outro professor do programa afirmou que os resultados parecem transparecer bem aquilo que se 
percebe no programa. Os demais respondentes não responderam ao e-mail, mas ninguém questionou a validade da pesquisa, seja em sua forma, seja em seu conteúdo.

\section{Resultados da pesquisa}

Pelas limitações de espaço do artigo, opta-se por não apresentar os trechos das entrevistas e também a breve descrição dos casos. Apresentam-se as questões de pesquisa e os resultados obtidos, marcando principais similaridades e diferenças em cada caso.

Quais os principais atores pessoais e institucionais considerados importantes para sustentar resultados acadêmicos superiores de um curso de doutorado em administração?

Com relação às similaridades encontradas nos dois casos, destacam-se os seguintes atores: docentes; alunos; coordenação dos cursos; agências de financiamento (CNPq e Capes); as próprias universidades em que se encontram os cursos. Com relação às diferenças encontradas, evidencia-se que na USP os seguintes atores destacam-se: parceiros externos em geral; a Fundação Instituto de Administração (FIA); o grupo de professores que coordena o Departamento de Administração e o Programa de Pós-Graduação em Administração e a secretaria do programa foram considerados atores/praticantes importantes em sustentar resultados acadêmicos superiores.

Quais as principais características e atividades dos doutorandos em administração durante seu curso, nos cursos de qualidade superior, consideradas como positivas na obtenção de resultados acadêmicos?

As similaridades encontradas nessa questão de pesquisa são muitas e nenhuma diferença significativa foi encontrada nas características e atividades dos doutorandos durante seu curso que são vistas como positivas para sustentar os resultados acadêmicos superiores em seu curso. As principais similaridades encontradas são as seguintes: dedicação exclusiva ao doutorado durante seu curso; não cursar as disciplinas e voltar para suas casas ou se envolver em outras atividades que o deixem distantes do programa; que produzam cientificamente e se engajem em pesquisas desde o início do curso e não apenas na tese; que estejam comprometidos com o programa e participem de suas atividades, especialmente de pesquisas; que acompanhem seus orientadores em sala de aula, em projetos e grupos de pesquisa; que possuam dedicação e disciplina para estudar durante a fase de créditos e para escrever durante a fase dissertativa; que participem de discussões e construções coletivas em ge- 
ral, sejam elas informais ou formais: em sala de aula, com seus orientadores, colegas ou em grupos de pesquisa.

Quais as principais características e atividades dos professores dos cursos de doutorado em administração, nos cursos de qualidade superior, consideradas como positivas na obtenção de resultados acadêmicos?

As similaridades encontradas nos dois casos estudados são: que os professores valorizem especialmente a pesquisa, mas também o ensino, a orientação e que estejam sempre em contato real com o mundo das organizações. Com relação à pesquisa, afirma-se que é importante serem pesquisadores produtivos inseridos em grupos de pesquisa. Sobre o ensino: valorizam-se aulas em formato de seminários, que gerem interessantes reflexões e discussões; e que deem aulas em todos os níveis (graduação, especialização, mestrado e doutorado). Sobre a orientação, ressalta-se que essa seja individual e que o orientador dê apoio e atenção constante aos seus orientandos na elaboração de seus trabalhos.

Com relação às principais diferenças encontradas, na USP ressaltam-se os professores que têm contatos e parcerias com empresas para que "abram as portas" das pesquisas aos alunos, que tenham grande foco em metodologia de pesquisa e didática e que gerem reflexões profundas nos doutorandos para que surjam pesquisas inovadoras. Na UFRGS, ressaltam-se os professores que não deixam que consultorias e aulas em MBAs tomem o tempo necessário para fazer pesquisa, que valorizam também seus orientandos Minter e Dinter, que tenham dedicação integral à vida acadêmica e que envolvam seus doutorandos em várias atividades, como escrever projetos, prestar contas, participar das salas de aula do professor e na gestão da produção científica.

Quais as principais características e atividades da coordenação dos cursos de doutorado em administração, nos cursos de qualidade superior, consideradas como positivas na obtenção de resultados acadêmicos?

As similaridades encontradas entre os casos estudados são: coordenar o programa e proporcionar incentivos com base nas métricas da Capes; articular, orientar e apoiar os diversos atores internos no sentido de beneficiar o programa; organizar os recursos do programa, para que os cursos de especialização financiem a pós-graduação stricto sensu; lidar com conflitos; valorização, material e simbólica, das pesquisas de qualidade; um foco nos processos de seleção de professores e alunos; estar atento a prazos e normas em geral.

Entre as principais diferenças encontradas, na USP citam-se como importantes atividades da coordenação: trabalhar de acordo com as normas internas da USP que regem a pesquisa e administrar o dia a dia com visão de futuro. Por outro lado, no curso de doutorado em administração da UFRGS, 
ressalta-se a importância da coordenação estar sempre próxima aos professores e alunos, cuidando para que não dispersem energia em atividades paralelas à pesquisa.

Quais as principais características organizacionais dos programas de pós-graduação em administração, nos cursos de doutorado de qualidade superior, consideradas como positivas na obtenção de resultados acadêmicos?

As similaridades encontradas nessa questão entre os dois casos estudados foram: foco em produção científica de qualidade nacional e com inserção internacional; política de incentivo financeiro às publicações; qualidade do corpo docente e discente; pessoal comprometido com o constante aumento da qualidade do programa; boa infraestrutura; alto nível de exigência; investir os recursos da especialização e dos MBAs na pós-graduação stricto sensu; liberdade para os pesquisadores investigarem seus temas de interesse.

Com relação às principais diferenças encontradas no programa de pósgraduação da USP, afirma-se que a secretaria do programa foi evidenciada como relevante para sustentar os resultados superiores. No programa de pósgraduação em administração da UFRGS, as diferenças encontradas que são interpretadas como relevantes para sustentar a qualidade do curso de doutorado são as seguintes: a heterogeneidade dos professores e suas diferentes visões sobre a administração; a postura de evitar a endogenia; a rotatividade dos professores no cargo de coordenação; a busca por atrair professores de dedicação exclusiva e com foco exclusivo na pesquisa.

Quais as principais características da instituição universitária em que estão alocados esses cursos de qualidade superior, consideradas como positivas na obtenção de resultados acadêmicos?

Com relação às similaridades encontradas, evidencia-se o fato de serem universidades grandes, tradicionais e reconhecidamente produtoras de pesquisas de qualidade. Com relação às principais diferenças encontradas na USP, os seguintes fatores foram considerados positivos para sustentar os resultados do curso de doutorado em administração: a indissociabilidade histórica entre ensino, pesquisa e extensão, juntamente com a legitimidade social da universidade, que proporciona muitas parcerias e financiamentos para pesquisa, também aliada a sua ótima infraestrutura. No caso da UFRGS, a sua tradição republicana com respeito aos espaços plurais e também seu alto nível de exigência em todos os cursos foram citados como características positivas para sustentar os resultados acadêmicos do doutorado em administração.

Quais as principais práticas realizadas na interação entre os diferentes atores organizacionais - coordenadores de curso, professores, alunos, membros da instituição de ensino e mesmo parceiros externos - nos cursos de 
doutorado nos programas de qualidade superior, consideradas como positivas na obtenção de resultados acadêmicos?

Entre as similaridades encontradas, destacam-se as seguintes: grupos de pesquisa em constante atividade; eventos sociais, formais e informais, em que haja interação entre os diferentes atores; processo seletivo rigoroso; atividades e núcleos de apoio; grupos de estudos; preocupação com prazos; gestão da produção científica. Aqui vale a pena destacar a prática coletiva dos grupos de pesquisa. É marcadamente a prática mais citada pela coordenação dos cursos, pelos professores e pelos doutorandos nos dois casos estudados. Todos respondentes, em algum momento das entrevistas, falaram sobre os grupos de pesquisa, mesmo que não respondendo diretamente a essa questão. Percebese que a autonomia dos grupos de pesquisa, a interação que é gerada entre os diferentes atores e sua constante atividade, é o que gera o maior número de discussões e publicações científicas.

No que diz respeito às diferenças encontradas, no curso de doutorado da USP, duas práticas coletivas que se destacaram foram o Semead e a seminário de integração para os alunos. No caso da UFRGS, a prática coletiva que se destacou foi o compartilhamento do poder.

\section{Complementos dos resultados}

Para complementar os resultados, seguem algumas evidências encontradas na pesquisa empírica que, embora não respondam a nenhuma pergunta de pesquisa específica e não sejam necessariamente compartilhadas pela maioria dos entrevistados, emergiram do trabalho de campo e mostraram-se relevantes para ajudar na compreensão do fenômeno em estudo. São observações adicionais que surgiram nas respostas dos entrevistados e com base em observações não participantes. Servem como forma de resumir os resultados apresentados, ajudar na explicação dos casos estudados e complementar as informações apresentadas.

No caso da USP, muitos entrevistados falam do desafio de ser um grande programa e manter a qualidade. Todos dizem que ser um curso da USP, estar em um programa de pós-graduação de qualidade, ter uma tradição de pesquisa historicamente reconhecida e legitimidade institucional ajudam a manter uma alta qualidade do doutorado em administração. Percebem-se muitas oportunidades de fazer pesquisa na USP e grande proximidade entre alguns professores e alunos. Há uma alta produção científica que acontece em grupos de pesquisa, já que os doutorandos que "vivem" o programa partici- 
pam de mais de um grupo e produzem bastante com os professores através deles. É inegável que o parque industrial de São Paulo e a cultura da USP de integração com a comunidade empresarial facilitam muito a entrada dos pesquisadores nas organizações e financiamentos privados para pesquisa: há um número significativo de consultorias e pesquisas andando em paralelo. Percebe-se na fala dos entrevistados um grande comprometimento dos atores em manter a excelência do programa, conscientes de seu papel de destaque no cenário nacional. Um dos professores afirmou que, embora possam haver críticas ao sistema de avaliação da Capes, o papel dessa instituição é muito mais positivo do que negativo e que a pós-graduação no Brasil não seria o que é sem o trabalho da Capes. Percebe-se que grande parte dos professores e alunos já são oriundos da própria USP, o que acaba por refletir a endogenia que foi expressa na última avaliação da Capes, mas isso não parece incomodar o conjunto dos entrevistados.

No caso da UFRGS, os padrões ficam difíceis de serem estabelecidos, já que há uma diversidade enorme de visões acerca de todas as perguntas que foram feitas. Os orientadores e colegas de grupo de estudos são citados como importantes atores e alguns não conseguem identificar atores, dizem que todos são importantes, que é a coletividade que faz a diferença. Muitos dizem ser importante que os professores façam estágio pós-doutoral e doutorandos façam o sanduíche para manter a qualidade do programa. Alguns professores dizem que poderiam existir mais trabalhos coletivos, que a estrutura física e organizacional não favorece, mas que isso impulsionaria ainda mais o programa. Alguns entrevistados afirmaram que estar em um eessencialmente agrícola e de industrialização tardia ajudou porque não tinha consultoria para dar e a atenção foi voltada à pesquisa. Determinados professores também afirmaram que há outros programas em que os recursos das especializações ficam quase que exclusivamente com os professores e, na UFRGS, apenas 30\% ficam com os professores e o restante é investido no programa. $O$ fato de isso acontecer e mesmo assim os professores serem criticados por darem aula na especialização é desmotivador para alguns. Muitos afirmam que o estímulo à pesquisa deixa professores e alunos muito próximos. A alta exigência do programa é citada como algo que choca os alunos e que frequentemente os doutorandos têm traumas psicológicos durante o curso. A leitura e as discussões teóricas em sala de aula, em grupos de estudos, em grupos de pesquisa e em eventos informais foram muito valorizadas por grande parte dos entrevistados.

Percebe-se também que mesmo perante as divergências epistemológicas, teóricas e também ideológicas entre os professores, há um grande comprometimento do corpo docente com o aumento constante da qualidade do 
programa e um respeito muito grande à diversidade de formação e de pensamento. Foi evidenciada uma preocupação significativa no sentido de construir uma imagem de seriedade científica ao programa. Por outro lado, foi evidenciada uma preocupação com o programa não ter uma identidade específica que permita dizer que o programa é bom "nisso ou naquilo", já que há uma grande generalidade. Os critérios de número máximo de orientandos estabelecidos pela Capes foram criticados por alguns, pois dizem que poderiam facilmente orientar mais doutorandos e mestrandos sem afetar a qualidade do trabalho. Uma possível endogenia futura foi percebida como fator que pode impedir o desenvolvimento futuro do programa, já que um professor afirmou que ex-alunos acabam tendo vantagem nos concursos. Alguns professores afirmam ser muito importante que haja mais trocas internas e externas, ou seja, entre os professores e alunos do programa, entre linhas de pesquisa e com outros núcleos de pesquisa fora do PPGA e da UFRGS e do Brasil. A maioria dos professores foi muito enfática ao falar sobre a seriedade de seus trabalhos, da vida de um professor de doutorado e evidenciou enorme satisfação pela vida acadêmica. Todos os doutorandos mostraram-se preocupados com a atual limitação do PPGA de recursos para congressos e afirmam que isso irá prejudicar o programa a longo prazo. Quase todos os entrevistados mostraram-se comprometidos em aumentar a nota do programa de 6 para 7, o que quase foi conseguido na última avaliação da Capes. As pressões institucionais da Capes foram identificadas como muito importantes para o desenvolvimento do programa.

Entre as similaridades encontradas nos dois casos estudados, a proximidade entre professores, alunos e a coordenação do programa e as trocas sociais que ocorrem no contato constante são vistas nesses dois programas como grandes responsáveis pelos resultados superiores. A interação em grupos de pesquisa, em sala de aula, em discussões formais e informais entre os professores e em grupos de estudos acabam por gerar muitas ideias para pesquisas e colaboração entre alunos e professores. O comprometimento dos professores, alunos e da coordenação com o programa é expresso como altamente significativo para os resultados do programa. A alta exigência dos dois programas de doutorado também é ressaltada. Percebe-se que todos os entrevistados têm consciência da qualidade dos seus programas, preocupação com a imagem institucional do programa de pós-graduação e do seu papel de liderança no cenário nacional e sua busca por uma inserção internacional cada vez maior. Estágios pós-doutorais e doutorados sanduíches são vistos como atividades importantes, bem como uma postura de internacionalização cada vez maior por parte de todos. As agências de fomento, financiamen- 
to e de regulamentação, tanto externas como internas às universidades, são apontadas em quase todas as entrevistas como vitais para os resultados do programa. Por serem programas de qualidade reconhecida, atraem alunos acima da média e podem conceder mais bolsas aos doutorandos, o que acaba por ajudar na sustentação da qualidade dos programas. Como muitos doutorandos dedicam-se exclusivamente ao programa e publicam muitos trabalhos científicos com colegas e professores durante o seu curso, isso eleva a qualidade do programa.

Entre as diferenças encontradas, ressalta-se que a USP é a maior e mais importante universidade brasileira, está inserida no maior parque industrial do país, na maior cidade brasileira e a própria inserção que os professores e a instituição possuem na comunidade empresarial favorece muito a entrada dos pesquisadores nas organizações. Isso propicia muitos objetos de investigação e recursos para pesquisa, o que acaba por ser um diferencial do programa da USP, que é o maior programa de pós-graduação em administração do país. Há um reconhecimento social muito grande pela imagem da USP e a própria legitimidade da instituição atrai muitos recursos, projetos e bons professores e alunos. Há também um número significativo de pesquisas e consultorias andando em paralelo no programa de pós-graduação, 0 que gera recursos para os pesquisadores e volume de pesquisas. Percebe-se uma endogenia maior no programa, pesquisadores com uma postura mais pragmática, certa unidade de pensamento entre os entrevistados e evidencia-se que um grupo composto por alguns professores é muito importante na coordenação do programa e ocupa cargos em todo o departamento de administração da FEA-USP.

A UFGRS está em uma das maiores cidades do sul do Brasil, é uma das maiores e mais produtivas universidades federais brasileiras, está em um estado historicamente agrícola, de industrialização tardia, em uma cultura que valoriza muito o conhecimento e a educação. Percebe-se que isso influencia muito na postura de valorização da ciência e nas tentativas de empurrar as fronteiras do conhecimento no PPGA, bem como um receio de que as consultorias tomem o tempo da pesquisa científica rigorosa e de vanguarda. A diversidade de formação, de pensamento, divergências teóricas, epistemológicas e mesmo ideológicas são valorizadas pelos entrevistados, mas também vistas como algo que dificulta um número maior de trabalhos conjuntos. A rotatividade de professores nos cargos de coordenação, o comprometimento coletivo dos professores com o desenvolvimento do conhecimento e o gosto pela abstração teórica são evidenciados como muito significativos. 


\section{Considerações finais}

Como ensinam pensadores da área vinculados a diferentes tradições de pensamento, estudar estratégia é estudar os resultados organizacionais (Chakravarthy e White, 2002; Whittington, Johnson e Melin, 2004; Jarzabrowski, 2005), mesmo não partindo de uma epistemologia em que relações de causa-efeito lineares e a noção de intencionalidade sejam pressupostos da análise. Quando se estuda estratégia a partir da prática social, busca-se descobrir quais são os padrões de comportamento coletivos e individuais que se relacionam com os diversos tipos de resultados da organização. E mesmo com todos os desafios epistemológicos que isso gera, como a impossibilidade de um total distanciamento da realidade em que se está inserido, não se poderia descartar a visão dos praticantes da estratégia, aqueles atores que realmente fazem a estratégia no seu cotidiano.

Os resultados empíricos dessa pesquisa, longe de esgotar esse debate, apenas confirmam que uma visão unicamente econômica da estratégia e mesmo da possibilidade de uma escolha estratégica unicamente baseada em fatores econômicos é uma redução da complexidade que é a realidade organizacional. Aspectos técnicos e sociais se entrelaçam para constituir uma estratégia. E, além disso, um conjunto de eventos envolvendo concepção e execução da estratégia acontece em uma organização, e essas duas facetas devem ser levadas em conta, mesmo sabendo que, na prática, essa questão não se dá de forma dicotômica.

Não adianta apenas entender qual é a "estrutura" social e organizacional que condiciona a ação dos estrategistas, estejam eles posicionados em qualquer nível hierárquico da organização. Também não buscar entender apenas quais as ações dos estrategistas que são efetivas do ponto de vista de resultados visados. É necessário buscar esse entendimento, mas ir além e tentar compreender como essa estrutura social e organizacional se articula com a ação humana, como é reproduzida ou transformada na ação, como essas ações e estruturas se relacionam com os resultados organizacionais. E sabendo que os significados contruídos coletivamente em uma organização acerca desses próprios resultados, de suas ações, das estruturas nas quais eles estão inseridos e construindo todos os dias é vital para essa compreensão. Nesse sentido, quanto maior a riqueza de interpretações, especialmente no que diz respeito aos pontos convergentes sobre os aspectos históricos, sociais e econômicos de uma estratégia, mais se pode enriquecer a compreensão do fenômeno. Reduzir isso à economia é relegar a apenas uma disciplina uma realidade que é interdisciplinar por sua própria natureza. 
Se a estratégia é fruto da construção humana em uma organização, sabendo que essa construção se dá em um espaço social que tem características multifacetadas, um estudioso da estratégia, tendo a concepção dela como uma prática social, tem de buscar os diversos fatores que fazem essa estratégia acontecer. É necessário levar em consideração os fenômenos e as condições tanto para a formação quanto para a implementação de uma estratégia. Mais do que isso, torna-se ímpar aprender como essas condições possibilitam ou restringem o surgimento de padrões sociais em uma organização em que são considerados estratégicos.

Tendo essa concepção como fundamento, este trabalho buscou aumentar um pouco mais a compreensão do que é estratégia em cursos de doutorado de administração em duas instituições públicas. Sabendo que essas organizações são consideradas modelos no que diz respeito a resultados esperados, de acordo com os indicadores que mensuram esses resultados. E tendo consciência de que talvez a parte mais significativa desse conhecimento esteja, mesmo que de forma implícita, nas pessoas que fazem a estratégia existir nessas organizações.

\section{Referências}

BARDIN, L. Análise de conteúdo. Lisboa: Edições 70, 2006.

BERGER, P.L.; LUCKMANN, T. A construção social da realidade. Petrópolis: Vozes, 2003.

CAPES. Capes, 50 anos: depoimentos ao CPDOC/FGV. Organização de Marieta de Moraes Ferreira e Regina da Luz Moreira. Rio de Janeiro: Capes/FGV, 2001.

. Critérios de avaliação trienal - 2004-2007. 2008a. Disponível em: <www. capes.gov.br>. Acesso em: 25 mar. 2008.

. Estatísticas. 2008b. Disponível em: <www.capes.gov.br>. Acesso em: 6 maio 2008.

CHAKRAVARTHY, B.S.; WHITE, R.E. Strategy process: forming, implementing and changing strategies. In: PETTIGREW, A.; THOMAS, H.; WHITTINGTON, R. (Org.) Handbook of strategy and management. London: Sage, 2002.

CHIA, R.; MACKAY, B. Post-processual challenges for the emerging strategy-aspractice perspective: Discovering strategy in the logic of practice. Human Relations, v. 60, n. 1, p. 217-242, 2007. 
CRAIG, R.T. Communication as practice. In: SHEPHERD, G.J.; ST. JOHN, J.; STRIPHAS, T. Communication as... perspectives on theory. California: Sage Publications, 2006.

DIMAGGIO, P.J.; POWELL, W.W. The iron cage revisited: institutional isomorphism and collective rationality in organizational fields. American Sociological Review, v. 48, n. 2, p.147-160, 1983.

ECO, U. Como se faz uma tese. São Paulo, Perspectiva, 1977.

FESTINALLI, R.C. A formação de mestres em administração: Por onde caminhamos? Organização e Sociedade, v. 12, n. 35, p. 135-150, 2005.

GIL, A.C. Métodos e técnicas de pesquisa social. São Paulo: Atlas, 1999.

GODOI, C.K.; MATTOS, P.L. de. Entrevista qualitativa: instrumento de pesquisa e evento dialógico. In: GODOI, C.K.; BANDEIRA-DE-MELLO, R.; BARBOSA DA SILVA, A. (Org.). Pesquisa qualitativa em estudos organizacionais. São Paulo: Saraiva, 2006.

GODOY, A.S. Estudo de caso qualitativo In: GODOI, C.K.; BANDEIRA-DE-MELLO, R.; BARBOSA DA SILVA, A. (Org.). Pesquisa qualitativa em estudos organizacionais. São Paulo: Saraiva, 2006.

HALL, R.H. Organizações: estruturas, processos e resultados. São Paulo: Prentice Hall, 2004.

HELLMANN, C.; RASCHE, A. Strategy practices: what they are (not). 2007. Disponível em: <www.strategy-as-practice.org/> . Acesso em. set. 2007

IKEDA, A.A.; CAMPOMAR, M.C.; VELUDO-DE-OLIVEIRA, T.M. A pós-graduação em administração no Brasil: definições e esclarecimentos. Revista Gestão e Planejamento, ano 6, n. 12, p. 33-41, jul./dez. 2005.

JARZABKOWSKI, P. Strategy as practice: an activity-based approach. California: Sage, 2005.

; BALONGUN, J.; SEIDL, D. Strategizing: the challenges of a practice perspective. Human Relations, v. 60, n. 1, p. 5-27, 2007.

JOHNSON, G. et al. Strategy as practice: research directions and resources. London: Cambridge, 2007.

LOUNSBURY, M.; CRUMLEY, E.T. New practice creation: an institutional perspective on innovation. Organization Studies, v. 28, n. 7, p. 993-1012, 2007.

MEYER, J.; ROWAN, B. Institutionalized organizations: formal structure as myth and ceremony. American Journal of Sociology, v. 83, n. 2, p. 340-363, 1977. 
MINTZBERG, H.; AHLSTRAND, B.; LAMPEL, J. Safári de estratégia: um roteiro pela selva do planejamento estratégico. Porto Alegre: Bookman, 2000.

OLIVEIRA, F.B. de. Inovando na pós-graduação: A experiência do MBA da Eaesp/ FGV. Revista de Administração de Empresas (RAE), São Paulo, v. 36, n. 1, p. 6-12, jan./mar. 1996.

PEREIRA, R.C.F. et al. Doutorado em administração no Brasil: um estudo exploratório dos fatores relacionados ao conceito de doutor e das responsabilidades dos principais agentes envolvidos no curso de doutorado. In: ENCONTRO NACIONAL DA ASSOCIAÇÃO NACIONAL DE PESQUISA E PÓS-GRADUAÇÃO EM ADMINISTRAÇÃO, Brasília. Anais. Salvador: Anpad, 2002.

RAMOS, C. The development of MBAs and business schools in Latin América. Business Leardership Review, v. 1, Issue 2, July 2004.

RECKWITS, A. The status of the "material" in theories of culture: from "social structure" to "artefacts". Journal for the Theory of Social Behaviour, v.32, n. 2, p. 195-217, 2002a.

. Toward a theory of social practices: a development in culturalist theorizing. European Journal of Social Theory, v. 5, n. 2, p. 243-263, 2002b.

REMENYII, D. et al. Doing research in business and management. London: Sage, 2002.

SAUERBRONN, F.F.; OLIVEIRA, F.B. de. Trajetória, desafios e tendências na articulação pedagógica entre a graduação e pós-graduação de administração e administração pública no Brasil. In: ENCONTRO DE ENSINO E PESQUISA EM ADMINISTRAÇÃO E CONTABILIDADE, Recife. Anais. Recife: Anpad, 2007.

SCHWARTZMAN, S. Formação da comunidade científica no Brasil. Rio de Janeiro: Finep, 1979.

SCOTT, R. W. Institutions and organizations. Thousand Oaks, CA: Sage Publications, 2001.

. Organizations: rational, natural and open systems. Upper Saddle River, NJ: Prentice Hall, 2003.

TRIVIÑOS, A.N.S. Introdução à pesquisa em ciências sociais. São Paulo: Atlas, 1994.

WILSON, D.C.; JARZABKOWSKI, P. Pensando e agindo estrategicamente: novos desafios para a análise estratégica. Revista de Administração de Empresas (RAE), São Paulo, v. 44, n. 4, p. 11-20, 2004.

WHITTINGTON, R. Strategy as practice. Long Range Planning, v. 29, n. 5, p. 731735, 1996. 
. O que é estratégia. São Paulo: Pioneira, 2002.

. Estratégia após o modernismo: recuperando a prática. Revista de Administração de Empresas (RAE), São Paulo, v. 44, n. 4, p. 44-53, 2004.

. Completing the practice turn in strategy research. Organization Studies, v. 27, n. 5, p. 613-634, 2006.

. Strategy practice and strategy process: family differences and the sociological eye. Organization Studies, v. 28, n. 10, p. 1575-1586, 2007.

; JOHNSON, G.; MELIN, L. The emerging field of strategy practice: some links, a trap, a choice and a confusion. In: Egos Colloquium, Slovenia, 2004.

YIN, R.K. Estudo de caso: planejamento e métodos. Porto Alegre: Bookman, 2001. 